\title{
Tensiones entre ficción e historiografía: los casos de La tierra del fuego, de Sylvia Iparraguirre y $E l$ libro de Daniel, de E. L. Doctorow
}

\section{Tensions between fiction and historiography. The cases of La tierra del fuego, by Sylvia Iparraguirre and El libro de Daniel, by E. L. Doctorow}

\section{Tensões entre ficção e historiografia. Os casos de La Terra do Fogo, de Sylvia Iparraguirre e El libro de Daniel, de E. L. Doctorow}

Cristopher Montero Corrales

Escritor

Recibido: 17/05/2018 Aceptado: 18/08/2018

Resumen

Este artículo trata sobre las tensiones entre historiografía y ficción en la literatura, específicamente en la estética textual posmoderna. Al inicio plantea generalidades del debate que han permitido homologar los textos históricos y ficcionales, para posteriormente tratar el concepto de metaliteratura o autorreferencialidad. Se concluye analizando los textos La tierra del fuego de Sylvia Iparraguirre (2000) y El libro de Daniel de E.L. Doctorow (2009)

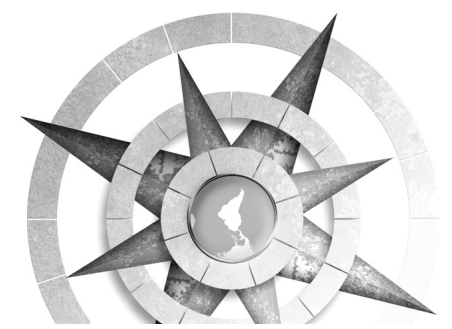

DOI: https://doi.org/10.15359/tdna.34-64.2

Julio-diciembre, 2018 Vol. 34, N. ${ }^{\circ} 64$ como libros que se constituyen a partir de estas tensiones entre historia/ficción y metaliteratura.

Palabras clave: Posmodernidad, metaliteratura, ficción, historia, parodia, E.L. Doctorow y Sylvia Iparraguirre

\section{Abstract}

This article deals with the tensions between historiography and fiction in literature, specifically in postmodern textual aesthetics. Initially, it poses generalities of the debate that have made it possible to homologate historical and fictional texts. Later, it analyzes the concept of meta literature or self-referentiality. It concludes with the analysis of the texts Tierra del fuego by Silvia Iparraguirre (2004) and El Libro de Daniel by E. L. Doctorov (2009) as texts that are 
constituted from these tensions between history/fiction and metaliterature.

Keywords: Postmodernity, meta-literature, fiction, history, E.L. Doctorow, Sylvia Iparraguirre.

\section{Resumo}

Este artigo trata das tensões entre historiografia e ficção na literatura, especificamente na estética textual pós-moderna. Inicialmente, apresenta generalidades do debate que possibilitaram a homologação de textos históricos e ficcionais. Posteriormente, analisa o conceito de meta-literatura ou auto-referencialidade. Conclui analisando os textos Tierra del fuego de Silvia Iparraguirre (2004) e El Libro de Daniel de E. L. Doctorov (2009) como textos constituídos a partir dessas tensões entre história / ficção e metaliteratura.

Palavras chave: Posmodernidade, metaliteratura, ficção, história, E.L. Doctorow, Sylvia Iparraguire.

Según Hayden White (2011) en el libro La ficción de la narrativa una de las características de la posmodernidad, esta reacción a la modernidad, es que la credibilidad que tuvo el conocimiento histórico en el siglo XIX o la novela realista, tiene un decaimiento. Esta suspensión de la credibilidad en el conocimiento histórico se da ya que en la posmodernidad se pone en cuestión el conocimiento, la posibilidad de conocer un hecho o la realidad de manera cabal o inclusive a uno mismo.
Hay que recordar que este valor que se le da a la historia viene de épocas antiguas, ya Aristóteles (2004) mencionaba que el poeta a diferencia del historiador no tiene ninguna obligación de apegarse a los sucesos históricos. También, las advertencias de Platón en el Ion sobre los poetas, ya que eran poseídos por las musas y abandonados por el buen sentido.

Claramente, deja al historiador con un apego cabal a los sucesos, y al poeta con la posibilidad de ficcionalizar, es decir, separar un texto de su referente empírico y privilegiar sus cualidades estéticas. $\mathrm{O}$ como lo afirma Umberto Eco con respecto a las verdades hermenéuticas:

"el mundo de la literatura es tal que nos inspira la confianza de que hay algunas proposiciones que no pueden ponerse en duda, $y$ nos ofrece, por lo tanto, un modelo (todo lo imaginario que quieran) de verdad" (2013, pág. 15).

Después del modernismo, la estética posmodernista del texto no solo diluye las nociones tradicionales de las clases literarias, o de las bellas artes, sino que esta estética difumina las nociones tradicionales en distintos campos, como por ejemplo: la historia y la ficción.

Como afirma Jameson: "Tampoco es difícil ver por qué ha sido así.

28 Tensiones entre ficción e historiografía: los casos de La tierra del fuego, de Sylvia Iparraguirre y El libro de Daniel, de E. L. Doctorow Cristopher Montero Corrales

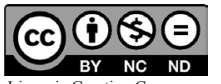

Licencia Creative Common Atribucion-No-Comercial
SinDerivadas 3.0 Costa Rica

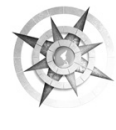


Los géneros son instituciones literarias, o contratos sociales entre un escritor y su público específico, cuya función es especificar el uso apropiado de un artefacto cultural particular” (1989, pág. 86).

Es de suponer que la problematización de los géneros, de las especialidades o de los campos, proponga nuevas fronteras, nuevas formas de relación: eso es una nueva frontera.

De esta forma, se comprende la escritura histórica como un discurso narrativo más, que responde a intereses y a luchas de poder como otros discursos. Se parte del postulado que entre hecho y ficción no hay diferencia alguna y, que al ser escritura, ya sea histórica o literaria son construcciones lingüísticas. Su única realidad es el lenguaje. Esto funciona como código maestro o clave interpretativa, según Jameson es la hermenéutica de los estructuralismos clásicos y también se halla hasta el exacerbamiento en el Foucault De lenguaje y literatura (1996).

Estos postulados han permeado a autores que no reivindican la posmodernidad como Terry Eagleton (2007) que considera al poema un hecho social.
Y si la única realidad es el lenguaje, entonces la escritura, a lo largo del tiempo, toma un papel de suma importancia ya que sería la ejecución que lo permite, que permite esta realidad.

Esta importancia de la escritura en la actualidad ha sido facilitada desde postulados modernos. Desde Bajtín se dejaron de entender los textos de forma aislada. Las categorías que permitieron esto, según Julia Kristeva (1997) son: estatus de la palabra, ambivalencia, intertextualidad, dialogismo, entre otras. Esto permitió dejar de interpretar la labor del escritor como un acto centrado en el individuo, sin conexión alguna, lejano de su contexto cultural, de la subjetividad y de sus lecturas:

"Así el dialogismo bajtiniano designa a la escritura como subjetividad y como comunicatividad o, mejor dicho, como intertextualidad: frente a ese dialogismo, la noción de "persona-sujeto de la escritura" empieza a desvanecerse para cederle el puesto a otra, la de la "ambivalencia de la escritura"' (Kristeva, 1997, pág. 6).

Los postulados posmodernos son una afrenta contra cierto objetivismo moderno que en su pretensión de distancia de sus referentes (para conseguir imparcialidad) esconden de una forma u otra sus intereses: 
"La ausencia de esta autorreferencia, el texto histórico tradicional cae en la "ideología" de manera inevitable" (White, 2011, pág. 530).

Una forma de asumir esta crítica del objetivismo moderno es destacar la autorreferencialidad como parte del discurso y entender la historiografía también como ficción -en el tanto que es una construcción narrativa-, un artefacto constituido por el lenguaje. Esto no pretende desideologizar los discursos, pretende evidenciar sus intereses, darlos a conocer.

\section{Metaliteratura o autorreferencialidad}

Aunque ya en Bajtín-Kristeva hay elaboraciones que implican, justamente, la forma del insertarse el autor en los textos, la metaficción o autorreferencialidad implica una forma particular del artefacto textual. Las elaboraciones críticas o la creación del referente -ya no en un formato de crítica, paratexto o en la realidad exterior- pasan a ser parte del objeto textual. El tras bambalinas puesto en escena.

El debate general de la metaliteratura se centra en dos perspectivas, una como particularidad posmoderna y otra como rasgo presente en cualquier género o época.
Los diversos marcos teóricos y posturas en debate generaron a su vez dos acepciones en su aplicación al orbe estético: una restringida (como tropo posmoderno) y otra abierta (como dispositivo discursivo presente en cualquier género o época literaria). Asimismo, en la misma órbita semántica, especialmente aplicados a la novela, conviven los adjetivos autorreferencial, autoconsciente, autogenerado, narcisista, reflexivo, introvertido, ensimismado, descriptivo. No obstante, a pesar de la ambigüedad producida por su uso, parece haberse consolidado plenamente como ya dijimos el término metaficción, para denominar un universo cuyo principio constructivo se apoya en la noción de autorreferencia (Scarano, 2017, pág. 134).

Para el caso del presente texto, entenderemos lo metaficcional con la actualización contemporánea de la consigna de Horacio ("Sin escribir cosa alguna, enseñaré cómo se escribe; diré la misión y las reglas del poeta..."): "Al escribir, indagaré cómo escribo" (Scarano, 2017, pág. 133).

Se trata, por un lado, de reflexiones metaliterarias como parte de la obra literaria y, por otro lado, de la creación del referente empírico dentro del texto. No es necesario buscar el referente en la realidad fuera del

30 Tensiones entre ficción e historiografía: los casos de La tierra del fuego, de Sylvia Iparraguirre y El libro de Daniel, de E. L. Doctorow 
texto. La señalación es hacia sí mismo. Puesto en otras palabras: el texto podría responder a la pregunta, ¿en qué se inspira el autor para escribir?

Los relatos -contrario a Lyotard- no solo no se han acabado, sino que también podemos contar cómo contamos y exponer el texto y su engranaje formal. A mi parecer esta es otra de las formas de tensionar la historia y la ficción: las estrategias formales y críticas expuestas en un objeto artístico ficcional -que se ha separado de su referente empírico- porque problematiza otros géneros como el ensayo (la forma histórica) que han contado con un carácter más objetivo que la poesía por ejemplo.

Me parece que este énfasis, que existe en la posmodernidad, por un lado, de develar el aparataje creativo que constituye la obra y, por otro, reflexionar sobre la escritura en la obra, sí es una característica de la época posmoderna sin que esto signifique exclusividad de la posmodernidad. Ya que preguntarse si es característico "exclusivamente" de la posmodernidad, a mi parecer, es preguntar en clave moderna, como si fuera intención de la posmodernidad generar cosas totalmente nuevas, genuinas y transformar la historia en ruptura con la tradición sino justamente es la reelaboración de esas tradiciones y sus exageraciones lo que la define. Hutcheon lo define como parodia:

"Las representaciones paródicas exponen las convenciones del modelo y desnudan sus mecanismos mediante la coexistencia de dos códigos en el mismo mensaje" (Ziva Ben-Porat (1979) en Hutcheon).

Análisis textual:

Comparemos dos libros que para mi lectura y para la crítica pertenecen a manifestaciones literarias que problematizan las fronteras entre las formas, entre los géneros y entre la ficción y la historia.

En El libro de Daniel (2009) se percibe, a través del relato, un cambio de narrador de primera a tercera persona y posteriormente en las últimas páginas del libro el narrador lo asume. Expone esta estrategia advirtiéndole al lector que va a cambiar de perspectiva (comentario del narrador sobre las estrategias creativas). Evidencia que, aunque se narran hechos de importancia social para la historia de los Estados Unidos (tercera), también son personales (primera), no se puede separar la historiografía de la ficción, ya que la realización narrativa de lo que sucedió implica trabajos de la memoria y esto no es dado sin mediación, 
implica vincularse. En La tierra del fuego (2000), esta objetividad posmoderna funciona cuando el narrador acepta que no se cree capaz de dar cuenta fidedigna de los hechos y que su pensamiento va de un lugar a otro y que en última instancia, lo que quiere es contar su historia.

Aceptar esta imposibilidad total de objetividad moderna, es aceptar las visiones inexactas e incompletas de la historia.

Ambos libros comparten la ficción sobre personajes históricos de relevancia: El libro de Daniel sobre el presidente estadounidense, los Beatles o Walt Disney y La tierra del fuego sobre un famoso científico.

Ponerlos en cuestión, afirmar diálogos o perspectivas, o incluso agregar características o viajes al personaje que los referentes empíricos (sujetos históricos) no hicieron, es una forma de tensionar estos límites en el conocimiento histórico y la ficción. Un punto menos para la semántica mimética:

"La concepción esencialista de las réplicas es demasiado restrictiva, y abogaba por una concepción radicalmente no esencialista de la identidad inter-mundos. La semántica de la reescritura posmoderna confirma este postulado. Al igual que existe un Napoleón ficcional que perdió la propiedad esencial del Napoleón real de morir en Santa Elena, existe un Robinson Cruso (e) ficcional que murió durante el viaje de regreso a Inglaterra... por su propia naturaleza, la reescritura depende de la presencia de réplicas, pero no es preciso que su constelación de agentes sea extensionalmente idéntica a la del protomundo" (Dolezel, 1999, pág. 314).

El libro de Daniel muestra manifestaciones populares, conciertos famosos, una familia asesinada y versiones de la culpabilidad de espionaje. Utiliza formatos de diario, comunicados internos, el tipo de formato que la historiografía ha usado para establecer su "objetividad" y lo muestra claramente ficcionalizado, parodia ese tipo de formas.

De igual forma lo hace Iparraguirre en La tierra del fuego, donde para el siglo XIX una carta podría dar algún tipo de veracidad de una historia y la elaboración del libro en "Pliegos" resulta también una forma de tensionar los límites entre historia y ficción.

Ambos libros privilegian la autoridad de la experiencia, no como una forma de acceder a la verdad, sino una forma de acceder a información que dé sentido al presente. Este borramiento de fronteras de la

32 Tensiones entre ficción e historiografía: los casos de La tierra del fuego, de Sylvia Iparraguirre y El libro de Daniel, de E. L. Doctorow Cristopher Montero Corrales

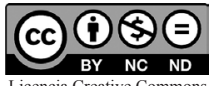

Licencia Creative Common Atribucion-No-Comercial
SinDerivadas 3.0 Costa Rica

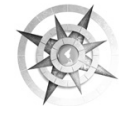


historiografía y la ficción funciona en ambos casos para redimirse y ordenar eventos traumáticos que constituyeron a los narradores: la muerte de los padres de Daniel y las atrocidades e injusticias contra la población indígena en La tierra del fuego durante la conquista y la masacre de los pueblos originarios en América.

Ambos textos calzan a la perfección con el concepto de parodia posmoderna, reescriben la historia críticamente y esto a su vez les resta poder a discursos oficiales con respecto a periodos traumáticos de sociedades. Su forma crítica restringe las atmósferas nostálgicas. Efectivamente, estamos ante textos que los recursos de la teoría contemporánea nos permiten entender y describir, como por ejemplo, la parodia:

"En vez de eso, a través de un doble proceso de instalación e ironización, la parodia señala cómo las representaciones presentes vienen de representaciones pasadas y qué consecuencias ideológicas se derivan tanto de la continuidad como de la diferencia. La política de la parodia posmoderna". (Hutcheon, 1993, pág. 1).

Estos textos tensionan los convencionalismos entre ficción e historia, entre las formas y expone mucho del aparataje formal que permite la escritura de las obras. Estamos ante textos que, a mi parecer, reflejan una serie de recursos exagerados en la contemporaneidad que permiten la creación de escritos tan creativos e inventivos.

\section{Referencias}

Aristóteles. (2004). Poética. Buenos Aires: Colihue Universidad.

Doctorow, E. (2009). El libro de Daniel. Barcelona: Miscelánea Editorial.

Dolezel, L. (1999). Heterocósmica. Ficción y mundos posibles. Madrid: Arco/libros, S.L.

Eagleton, T. (2007). Cómo leer un poema. Madrid: Ediciones AKAL.

Eco, H. (2013). Sobre literatura. España: Debolsillo.

Foucault, M. (1996). De lenguaje y literatura. Barcelona: Ediciones Paidós.

Hutcheon, L. (1993). La política de la parodia posmoderna. Revista Criterios, La Habana. Julio 1993, pp. 187-203.

(1985). A Theory of Parody: The Teachings of Twentieth-Century Art Forms. Londres/ Nueva York: Methuen.

Iparraguirre, S. (2000). La tierra del fuego. Argentina: Alfaguara.

Jameson, F. (1989). Documentos de cultura, documentos de barbarie. La narrativa como acto social simbólico. Madrid: Visor Distribuciones S.A. 
Kristeva, J. (1997). La palabra, el diálogo y la novela. UNEAC. Recuperado el 13 de febrero de 2017 de https:// es.scribd.com/doc/91306311/Kristeva-Bajtin-La-Palabra-El-Dialogo-y-La-Novela.
Scarano, L. (2017). Escribo que escribo: de la metapoesía a las autopoéticas. Recuperado el 9 de enero de 2018 de https://papiro.unizar.es/ojs/index.php/ tropelias/article/view/2217

White, H. (2011). La ficción de la narrativa. Ensayos sobre historia, literatura y teoría 1957-2007. Buenos Aires: Eterna Cadencia. 